Sharif University of Technology
Scientia Iranica
SCIENTIA
IRAN ICAA

\title{
Effect of steel and concrete coupling beams on seismic behavior of RC frame accompanied with coupled shear walls
}

\author{
H. Akbarzadeh Bengar ${ }^{\mathrm{a}, *}$ and R. Mohammadalipour Aski ${ }^{\mathrm{b}}$ \\ a. Department of Civil Engineering, University of Mazandaran, Babolsar, Iran. \\ b. Department of Civil Engineering, Shomal University, Amol, Iran.
}

Received 18 August 2015; received in revised form 14 May 2016; accepted 19 July 2016

\author{
KEYWORDS \\ $\mathrm{RC}$ coupled shear \\ wall; \\ Concrete and steel \\ coupling beam; \\ Seismic behavior; \\ Nonlinear analysis; \\ Response modification \\ factor; \\ Displacement \\ amplification factor.
}

\begin{abstract}
Construction of diagonal reinforcement in concrete coupling beam is difficult; therefore, its replacement is steel coupling beam. A review of the related literature shows that a few studies have considered seismic behavior of RC coupled wall with steel coupling beam. In this paper, the influence of an increase in building height on the seismic nonlinear behavior of dual structural systems in the form of RC frames accompanied with RC coupled shear walls once with concrete, and then with steel coupling beam was investigated. Therefore, the buildings with 7, 14, and 21 stories and containing RC coupled wall systems with concrete and steel coupling beams were used to perform the pushover analysis with different load patterns. Some seismic parameters, such as ductility factor, response modification factor due to ductility, over-strength factor, response modification factor $(R)$, and displacement amplification factor $\left(C_{d}\right)$ were studied. Regarding the results, the response modification factor for the mentioned structural system is higher than the values used in codes of practice for seismic resistant design of buildings. In addition, the displacement amplification factor and the response modification factor increase as the structure height decreases and the values of these factors at steel coupling beam structures are higher than those at concrete coupling beams.
\end{abstract}

(C) 2017 Sharif University of Technology. All rights reserved.

\section{Introduction}

Concrete moment-resisting frames accompanied with reinforced concrete shear walls are popular in high-rise structures [1]. Shear walls are structures that provide resistance against lateral loads and their position with architectural and installation requirements leads to repeated openings from floor to floor throughout the height of the system, and result is isolated walls

*. Corresponding author. Tel.: +98 1135302902 E-mail address: h.akbarzadeh@umz.ac.ir (H. Akbarzadeh Bengar)

doi: $10.24200 /$ sci. 2017.4159 connected by coupling beams. Coupling beams provide a transfer of vertical forces between adjacent walls, creating a coupling action that resists a portion of the total overturning moment induced by the base shear [2]. This coupling action has two useful effects: it reduces the moments that must be resisted by the individual walls, and therefore results in a more efficient structural system at an elastic state. Then, it provides a means by which energy is dissipated over the height of the wall system as coupling beams undergo inelastic deformations [3]. Coupling beams must behave in a ductile manner, yield before the wall piers, and exhibit significant energy dissipation characteristics. Therefore, coupling beams should be designed to avoid over-coupling, which causes the sys- 
tem to act as a single wall. In addition, light coupling should be avoided as it causes the system to behave like two isolated walls [3-10]. Several researchers [11, 12] have investigated the issue of improving the energy absorption capacity and ductility of reinforced concrete coupling beams. For span-to-depth ratios less than 2, due to shear behavior and high-energy absorption, a method was developed by Paulay and Binney [11] and Park and Paulay [12] using specially detailed diagonal reinforcement, but this detail may be very difficult to construct. In order for reinforced concrete coupling beams to possess a stable hysteretic response under seismic loading, a high level of detailing, including confinement of beam concrete and adequate containment of steel reinforcement in the connected walls, must be provided [13]. This leads to deep beams with heavy reinforcement, requiring extra formwork and much labor in construction. For this reason, different techniques have been proposed instead of conventional coupling beams [13-23]. Some researchers have turned to steel coupling beams, with their ends embedded in two adjacent walls, instead of reinforced concrete coupling beams [13,16-20]. Steel coupling beams possess the necessary combination of ductility, strength, and stiffness, needed for providing the best overall structural performance and suitable hysteretic response. They also provide a permanent alternative to reinforced concrete coupling beams that can be replaced after a severe earthquake. Furthermore, the advantages of steel coupling beams become apparent in cases where height restrictions do not allow for the use of deep reinforced concrete coupling beams or where concrete coupling beams cannot economically obtain the required stiffness and capacities. Coupling beams may be detailed to dissipate more portion of the input energy by flexure or shear, depending on the coupling beam length. In addition, it is more advantageous to design them as shear yielding members or shear critical, since such members have more desirable energy dissipation; such a choice is not possible for reinforced concrete coupling beams. El-Tawil et al. developed design recommendations for steel coupling beams in RC shear wall [20].

All previous studies have focused on examining the seismic response of steel coupling beam as a single element. However, seismic behavior of systems in the form of concrete moment-resisting frames accompanied with RC coupled shear walls with either concrete or steel coupling beam has not been thoroughly investigated. Therefore, it is necessary to investigate seismic behavior of buildings containing such structural systems. In this paper, the nonlinear behavior of the coupled shear wall with concrete and steel coupling beams has been evaluated. Some parameters, such as response modification factor $(R)$ and displacement amplification factor $\left(C_{d}\right)$, have been determined, like previous research on other structural systems [24-26]. Evaluations of the studies by Andrew Whittaker et al. clearly show that the response modification factor $(R)$ of structures varies widely as a function of building type, building height, and seismic zone. Values of strength factors must address these variations, and the influence of higher-mode effects must be studied further [27].

\section{Seismic behavior parameters of structures}

\subsection{Ductility factor}

There is no accurate definition for the ductility factor of Multiple Degrees-Of-Freedom (MDOF) structures. As shown in Figure 1, The ductility factor in the SDOF systems is a proportion of maximum lateral displacement to the yielding lateral displacement of structure (Eq. (1)). It is a measure of the global nonlinear response of a system. Moreover, it somehow explains the structure entrance into the nonlinear state:

$$
\mu=\frac{\Delta_{\max }}{\Delta_{y}}
$$

According to Figure 1, the relation between the base shear and displacement is not an elastic-perfectly plastic equation. The actual force-displacement response curve is idealized by a bilinear elastic-perfectly plastic response curve, and it defines the behavior factor parameters.

\subsection{Behavior factor parameters}

Seismic codes assume a reduction in design loads, and three components are generally taken into account (Eq. (2)): ductility, overstrength of a structure, and the difference in the levels of stresses (the last one is termed the allowable stress factor). This factor presents the ratio of maximum seismic force on a structure during ground motion if it remains elastic $\left(V_{e}\right)$ to the design seismic force $\left(V_{w}\right)$. Therefore, actual seismic forces or elastic forces $\left(V_{e}\right)$ are reduced by response modification

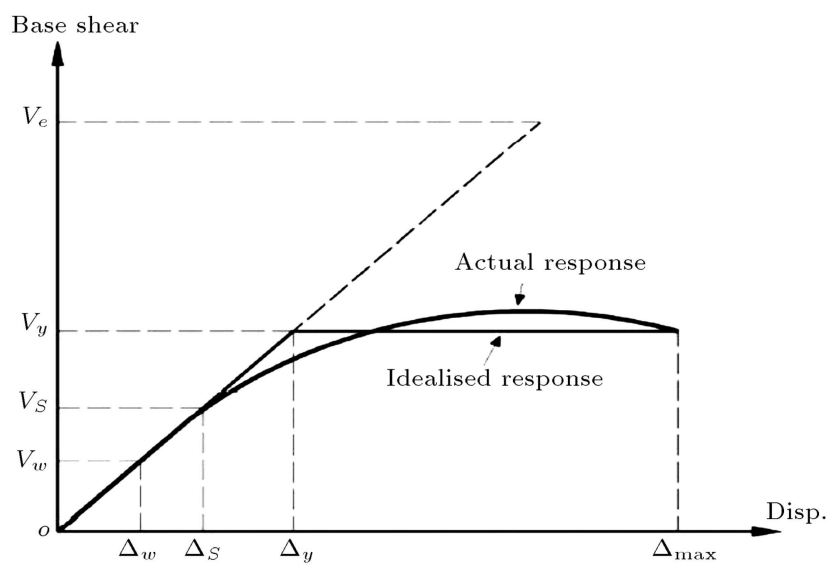

Figure 1. General structure response. 
factor " $R$ " to obtain design forces $\left(V_{w}\right)$. The basic flaw of code procedures is that they use linear methods, but rely on nonlinear behavior [28]:

$$
R=\frac{V_{e}}{V_{w}}=\frac{V_{e}}{V_{y}} \times \frac{V_{y}}{V_{S}} \times \frac{V_{S}}{V_{w}}=R_{\mu} \times R_{S} \times Y
$$

As mentioned above, usually real nonlinear behavior is idealized by a bilinear elastic-perfectly plastic response curve. $V_{\max }$ or $V_{e}$ corresponds to the elastic response strength of the structure, $V_{y}$ shows the yield force of structure, and $\Delta_{y}$ is the yield displacement. The maximum base shear in an elastic-perfectly plastic behavior is $V_{y}$ [29]. Response modification factor due to ductility is the ratio of maximum base shear considering elastic behavior, $V_{e}$, to maximum base shear in elastic-perfectly plastic behavior, $V_{y}$ (Eq. (3)). It is also called force reduction factor due to ductility:

$$
R_{\mu}=\frac{V_{e}}{V_{y}}
$$

The over-strength factor or response modification factor due to over-strength is defined as the ratio of maximum base shear in elastic-perfectly plastic behavior, $V_{y}$, to the first significant yield strength in structure, $V_{s}$ (Eq. (4)). It is also called force reduction factor due to over-strength:

$$
R_{S}=\frac{V_{y}}{V_{S}}
$$

To design an allowable stress method, the codes decrease the design loads from $V_{S}$ to $V_{w}$ and this is done by allowable stress parameter $(Y)$. $Y$ stands for the allowable stress factor, which is defined as (Eq. (5)) [30]:

$$
Y=\frac{V_{S}}{V_{w}}
$$

For the ultimate strength design, in this study, $Y$ equals 1 [29].

\subsection{Relation between the three parameters $\left(R_{\mu}, \mu\right.$, and $\left.T\right)$}

The response modification factor due to ductility $\left(R_{\mu}\right)$ is related to a number of parameters, many of which are dependent on characteristics of the structural system and some of them are independent of the structure. $R_{\mu}$ relies on the ductility factor of structure and performance characteristics in the nonlinear state. Some other factors that influence the relation between $R_{\mu}$ and $\mu$ are period of system, damping, materials, $P-\Delta$ effects, the load-deformation model in the hysteresis loops, and type of the soil that exists in the site. If we take this assumption that the ductility in structures with short periods is equal to those with longer periods, then the smaller and wrong $R_{\mu}$ is obtained. New Mark and Hall suggested the following equations (Eqs. (6)(8)) to calculate the response modification factor due to ductility [31]:

$$
\begin{aligned}
& R_{\mu}=1 \quad T<0.125 \mathrm{sec}, \\
& R_{\mu}=\sqrt{2 \mu-1} \quad 0.125 \mathrm{sec}<t<0.5 \mathrm{sec}, \\
& R_{\mu}=\mu \quad 0.5 \mathrm{sec}<T .
\end{aligned}
$$

Thus, for $(T>0.5 \mathrm{sec}), R_{\mu}$ is effectively equal to ductility factor $(\mu)$ of the structure.

\subsection{Displacement amplification coefficient $\left(C_{d}\right)$}

Many structural failures and collapses in earthquakes are brought about by excessive deformations which occur at the stories, i.e. structural and non-structural elements. Thus, one of the most important objectives of an appropriate seismic design is determination of relative actual displacement of the structures under severe earthquakes. In the seismic design codes, maximum inelastic relative displacement can be calculated by increasing the elastic displacement. As shown in Figure $1, C_{d}$ coefficient can be calculated as follows (Eq. (9)):

$$
C_{d}=\frac{\Delta_{\max }}{\Delta_{s}}=\frac{\Delta_{\max }}{\Delta_{y}} \times \frac{\Delta_{y}}{\Delta_{s}}=\mu \times R_{s} .
$$

$\Delta_{\max }, \Delta_{s}$, and $\Delta_{y}$ are shown in Figure 1.

\section{Coupling beams}

Coupling beams can be subjected to high loading and rotational demands under lateral loads (i.e., earthquake or wind). Conventionally RC coupling beams with longitudinal flexural and transverse shear reinforcement may be inadequate due to brittle failures in the form of diagonal or sliding cracking [32]. A number of coupling beam designs, such as diagonally reinforced concrete coupling beams $[11,12,33-35]$ and steel coupling beams $[15,19,36]$, have been proposed. The degree of coupling is a function of the strength and relative stiffness of the beam and wall. Coupling individual flexural walls brings about the lateral loadresisting behavior changes to one, where overturning moments are resisted partly by an axial compressiontension couple across the wall rather than by the individual flexural action of the walls. Therefore, coupling beams act like a fuse and will tolerate even severe earthquakes. However, in strong ground motion, they are not expected to behave rigidly; even coupling beams shall be flexible to dissipate energy $[37,38]$.

As mentioned above, the total resistant moment of coupled shear wall system depends on coupling ratio. 


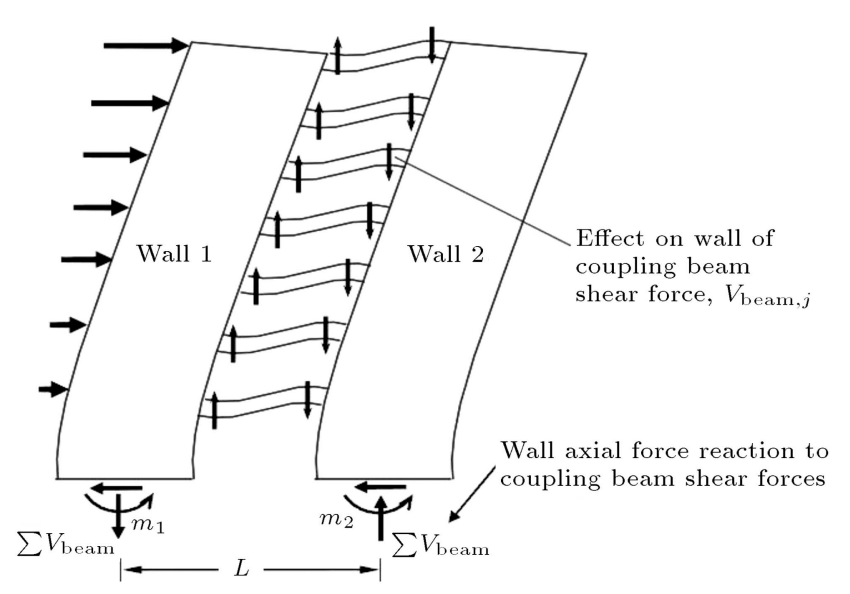

Figure 2. Definition of CR.

Coupling Ratio (CR) is defined as in the following equation:

$$
\mathrm{CR}=\frac{L \sum V_{\text {beam }}}{L \sum V_{\text {beam }}+\sum m_{i}},
$$

where $\sum V_{\text {beam }}$ is accumulation of coupling beam shears acting on each wall pier, $L$ is lever arm between the centroids of the wall piers, and $m_{i}$ is individual wall pier moment reaction (see Figure 2).

As mentioned above, since shear forces for seismic design of RC coupling beams are carried out by diagonal reinforcement, details of $\mathrm{RC}$ coupling beams may be very difficult to construct. Consequently, steel coupling beam is suggested instead. Steel coupling beams have similar behavior and provide the same structural role as link beams in Eccentrically Braced Frames (EBF).

\section{Steel coupling beam}

As noted earlier, it is more advantageous to design the coupling beams as shear-yielding members since a shear-critical steel coupling beam exhibits a more desirable mode of energy dissipation than a flexure critical steel coupling beam. Therefore, in this research, the coupling beams are designed to yield in shear, according to the method proposed by Harries et al. [15], in conjunction with the AISC Seismic Provisions [39] for shear links in an eccentrically braced frame. The steel coupling beam should be embedded in the wall to control cracking; therefore, its capacity can be developed. Number of methods may be used to calculate the necessary embedment length $[40,41]$. The equations, proposed by Marcakis and Mitchell, generally result in slightly longer embedment lengths.

\subsection{Basis of design provision}

Links are "fuse" elements of frame; the link rotation angle $\left(\gamma_{p}\right)$ is the inelastic angle between the link and beam outside of the link, when the total story drift is equal to the design story drift, $\Delta$. The link rotation

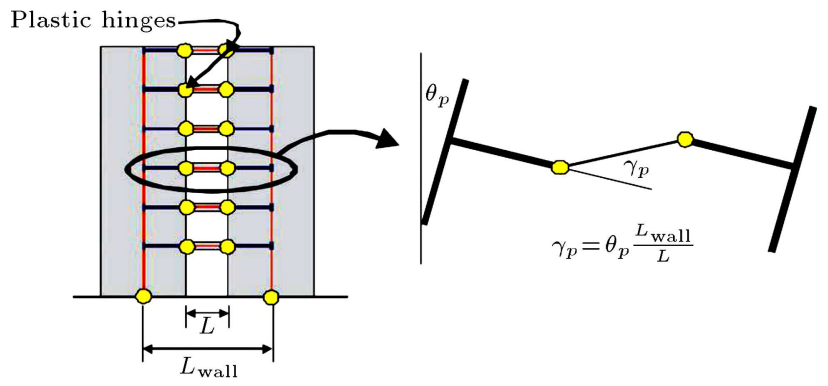

Figure 3. Determination of coupling beam angle of rotation [17].

angle shall not exceed the following value: for links of length $1.6 M_{p} / V_{p}$ or less: $0.08 \mathrm{rad}$ and for links of length $2.6 M_{p} / V_{p}$ or greater: $0.02 \mathrm{rad}$, where $M_{p}$ is nominal plastic flexural strength, and $V_{p}$ is nominal shear strength of an active link. Linear interpolation between the above values shall be used for links of length between $1.6 M_{p} / V_{p}$ and $2.6 M_{p} / V_{p}$. As can be seen in Figure 3 and according to the method proposed by Harries et al. [17], $\left(\gamma_{p}\right)$ can be obtained.

Links shall be I-shaped cross-sections (rolled wide-flange sections or built-up sections) or built-up box sections. HSS (i.e., hollow sections) shall not be used as links. Shear yielding will occur when $V=V_{p}=$ $0.6 F_{y} \times A_{w}$ and $M<M_{p}=Z_{b} \times F_{y}$ or $e \leq 1.6 M_{p} / V_{p}$, where $F_{y}, A_{w}$, and $Z_{b}$ are the I-shaped cross-section characteristics: yielding strength, section height, flange thickness, web thickness, and plastic section modulus, respectively. Shear yielding of steel links provides the best overall structural performance for strength, stiffness, and ductility. Coupled shear walls are expected to withstand significant inelastic deformations in the links when subjected to design earthquake. However, links shall be flexible to dissipate energy at strong ground motions. Design of steel coupling beams based on strength approach is according to the following equations:

$$
\begin{aligned}
& M(L R F D)=M_{D}+1.2\left(M_{L}+M_{E}\right) \\
& V(L R F D)=V_{D}+1.2\left(V_{L}+V_{E}\right) \\
& V_{n}=\min \left(V_{p}, \frac{2 M_{p}}{e}\right) \\
& \theta_{p}=\frac{0.7 R \Delta_{w}}{h} \\
& \gamma_{p}=\frac{L_{\text {wall }} \cdot \theta_{p}}{L}
\end{aligned}
$$

These three equations, i.e. $e \leq 1.6 M_{p} / V_{p}, \quad V$ $(L R F D) \leq 0.9 V_{n}, \gamma_{p} \leq 0.08$, have been checked for the design of equivalent steel coupling beams, where $M_{D}, M_{L}, M_{E}$ are flexural moments due to dead, live, and earthquake loads, respectively, also 
$V_{D}, V_{L}, V_{E}$ are shear forces due to dead, live, and earthquake loads, respectively, in coupling beam. $R$ is response modification factor [42], $\Delta_{w}$ is maximum relative lateral displacement of the story, $h$ is story height, $L_{\text {wall }}$ and $L$ are as shown in Figure 3 .

\section{Design and modeling}

\subsection{Overview of prototype structures}

In this study, six structural models are used for specifying the trend of this research defined as follows: 7-, 14-, 21 -storey buildings in the form of concrete momentresisting frame accompanied with reinforced concrete coupled shear wall, first with concrete, then with steel coupling beams (see Table 1). Also, as mentioned above (Section 3), the Coupling Ratio (CR) of these models is obtained, ranging from $25 \%$ to $40 \%$. The height of the first storey is $2.9 \mathrm{~m}$, the second $4 \mathrm{~m}$, and the rest $3.2 \mathrm{~m}$. According to Figure 4(a), shear walls in $Y$ direction have opening named coupled shear wall, but are solid in $X$ direction. The steel material used in the sections of the structural members is of ST37 type with yielding strength of $2400 \mathrm{~kg} / \mathrm{cm}^{2}$ and ultimate strength of $3700 \mathrm{~kg} / \mathrm{cm}^{2}$. The compressive strength of concrete material, $f^{\prime} c$, used in the shear walls, is $240 \mathrm{~kg} / \mathrm{cm}^{2}$, and yielding strength of steel bar is $4000 \mathrm{~kg} / \mathrm{cm}^{2}$. In order to calculate earthquake load, the spectrum dynamic method was used based on reference
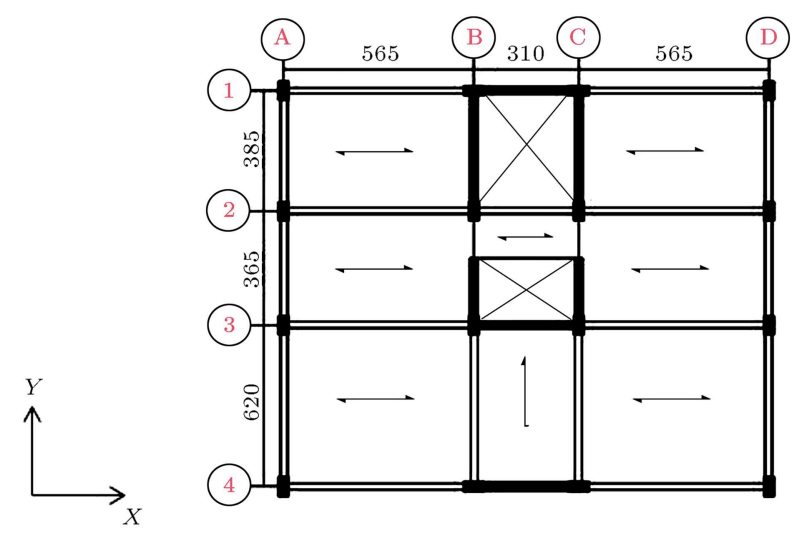

(a)
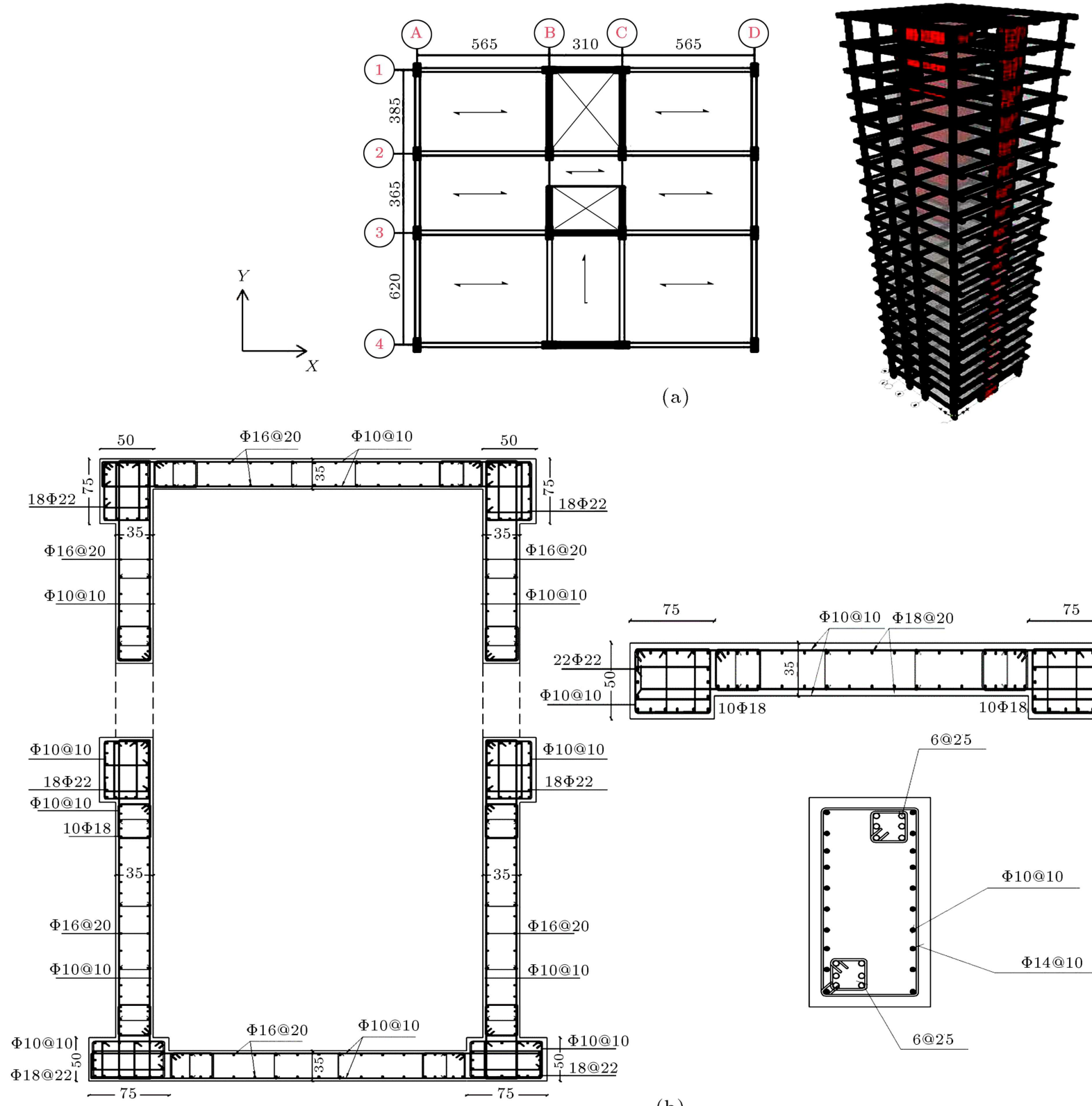

$75 \quad \Phi 10 @ 10 \quad \Phi 18 @ 20 \quad 75$
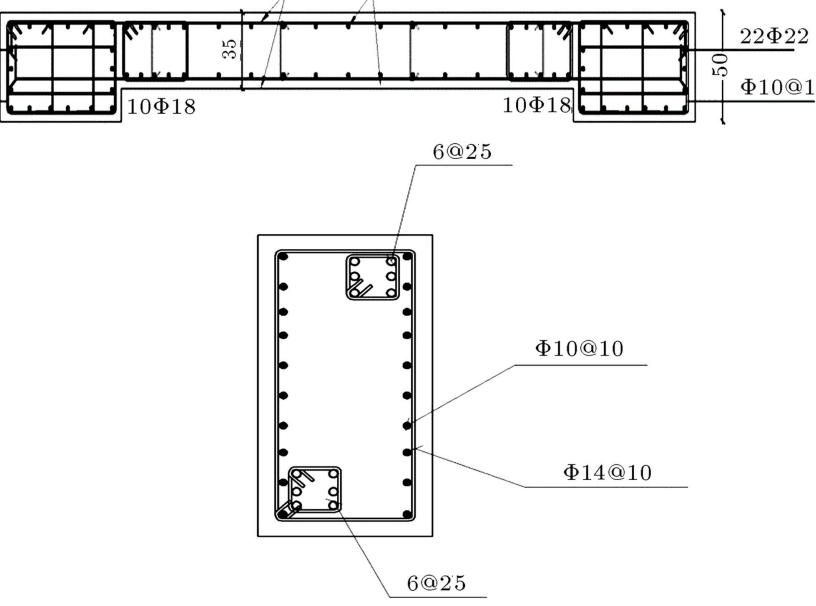

(b)

Figure 4. (a) The structural plan and elevation of the models. (b) Details of RC coupled shear wall and concrete coupling beam. 
Table 1. Dual systems under investigation.

\begin{tabular}{ccc}
\hline Number & Model & Symbol \\
\hline 1 & 7 stories with concrete coupling beam & 7 st-conc \\
2 & 14 stories with concrete coupling beam & 14 st-conc \\
3 & 21 stories with concrete coupling beam & 21 st-conc \\
4 & 7 stories with steel coupling beam & 7 st-steel \\
5 & 14 stories with steel coupling beam & 14 st-steel \\
6 & 21 stories with steel coupling beam & 21 st-steel \\
\hline
\end{tabular}

Table 2. Details of RC coupled shear wall and concrete coupling beam of buildings.

\begin{tabular}{|c|c|c|c|c|c|c|}
\hline \multicolumn{2}{|c|}{$\begin{array}{c}\text { Thickness of } \\
\text { shear wall }\end{array}$} & \multicolumn{3}{|c|}{$\begin{array}{c}\text { Details of } \\
\text { reinforcement bar }\end{array}$} & \multirow{2}{*}{\multicolumn{2}{|c|}{$\begin{array}{cc} & \text { Details of } \\
\text { reinforcement bar } \\
\text { Story } & \begin{array}{c}\text { Diagonal reinforcement } \\
\text { bar of each side }\end{array} \\
\end{array}$}} \\
\hline Story & $\begin{array}{c}\text { Thickness } \\
(\mathbf{c m})\end{array}$ & $\begin{array}{c}\text { Longitudinal bar } \\
\text { in web }\end{array}$ & $\begin{array}{c}\text { Horizontal } \\
\text { bar }\end{array}$ & $\begin{array}{l}\text { Longitudinal bar } \\
\text { on boundary zone }\end{array}$ & & \\
\hline \multicolumn{7}{|c|}{21 story } \\
\hline $1-2$ & 40 & $\Phi 18 @ 20$ & $\Phi 10 @ 10$ & $18 \Phi 25$ & $1-2$ & $6 \Phi 25$ \\
\hline $3-4$ & 35 & $\Phi 16 @ 20$ & $\Phi 10 @ 10$ & $18 \Phi 22$ & $3-4$ & $6 \Phi 25$ \\
\hline $5-6$ & 35 & $\Phi 16 @ 20$ & $\Phi 10 @ 10$ & $18 \Phi 18$ & $5-6$ & $4 \Phi 25$ \\
\hline 7 & 30 & $\Phi 14 @ 20$ & $\Phi 10 @ 10$ & $16 \Phi 18$ & 7 & $4 \Phi 25$ \\
\hline $8-12$ & 30 & $\Phi 12 @ 20$ & $\Phi 10 @ 10$ & $16 \Phi 16$ & $8-12$ & $4 \Phi 20$ \\
\hline $13-16$ & 25 & $\Phi 12 @ 20$ & $\Phi 10 @ 10$ & $16 \Phi 16$ & $13-16$ & $4 \Phi 18$ \\
\hline 17 & 20 & $\Phi 10 @ 20$ & $\Phi 10 @ 10$ & $12 \Phi 16$ & 17 & $4 \Phi 18$ \\
\hline $18-21$ & 20 & $\Phi 10 @ 20$ & $\Phi 10 @ 10$ & $12 \Phi 16$ & $18-21$ & $4 \Phi 16$ \\
\hline \multicolumn{7}{|c|}{14 story } \\
\hline $1-5$ & 30 & $\Phi 14 @ 20$ & $\Phi 10 @ 10$ & $16 \Phi 18$ & $1-5$ & $4 \Phi 25$ \\
\hline $6-9$ & 25 & $\Phi 12 @ 20$ & $\Phi 10 @ 10$ & $16 \Phi 16$ & $6-11$ & $4 \Phi 20$ \\
\hline $10-14$ & 20 & $\Phi 10 @ 20$ & $\Phi 10 @ 10$ & $12 \Phi 16$ & $12-14$ & $4 \Phi 18$ \\
\hline \multicolumn{7}{|c|}{7 story } \\
\hline $1-2$ & 25 & $\Phi 12 @ 20$ & $\Phi 10 @ 10$ & $16 \Phi 16$ & $1-2$ & $4 \Phi 25$ \\
\hline \multirow[t]{2}{*}{$3-7$} & 20 & $\Phi 10 @ 20$ & $\Phi 10 @ 10$ & $12 \Phi 16$ & $3-5$ & $4 \Phi 20$ \\
\hline & & & & & $6-7$ & $4 \Phi 18$ \\
\hline
\end{tabular}

Standard No. 2800 [42]. The American Institute of Steel Construction Specification [39] and American Concrete Institute Requirements (ACI 318-05) [43] were used to design steel members and intermediate $\mathrm{RC}$ shear wall and frame, respectively. Moreover, Eqs. (11)-(15) were employed to design steel coupling beam. For example, details of RC coupled shear wall and concrete coupling beam of the fourth story in a 21-story building are given in Figure 4(b). In addition, details of RC coupled shear wall and concrete coupling beam for all buildings are summarized in Table 2. After examining various sections of steel coupling beam, IPE400 was finally chosen for all the stories. Based on AISC 2010, links with length greater than or equal to $2.6 M_{p} / V_{p}$ and less than $5 M_{p} / V_{p}$ can be provided with intermediate web stiffeners placed at a distance of 1.5 times $b_{f}$ from each end of the link. Therefore, intermediate web stiffeners are used in steel coupling beam to prevent lateral buckling.

Three nonlinear static analysis approaches were used for each structural model in PERFORM3D software, described in the following. Structures were simulated in 3D (Figure 5). The moment-rotation characteristics of the plastic hinges for $\mathrm{RC}$ column and beam were obtained through section analysis using appropriate nonlinear constitutive laws. In this research, FEMA beam and column plastic hinge properties (FEMA356 2000) were assigned to nonlinear 


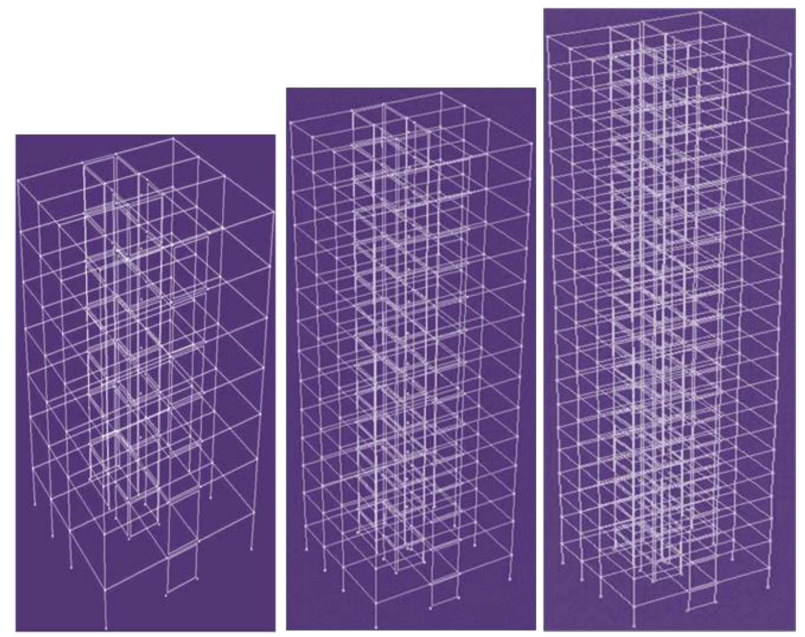

Figure 5. The structural models in PERFORM3D.

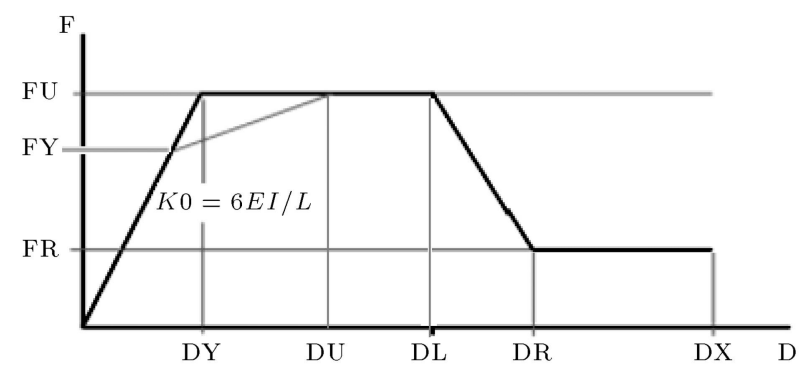

Figure 6. Modeling of the nonlinear behavior of RC beams and columns in PERFORM3D.

behavior of beams and columns in PERFORM3D software (Figure 6). Nonlinear characteristics of RC shear wall and coupling beam will be described in the next sections.

The distribution of horizontal loads over the structure height must be specified for static pushover analysis. In Uniform Nonlinear Static Procedure (UNSP), according to FEMA-356 [44], uniform load distributions over the building height were used. The difference between this procedure and Triangular Nonlinear Static Procedure (TNSP) is in their load pattern. In TNSP, the inverted triangular profile was used for displacement-based load pattern of storey masses, according to FEMA-356. For a high-rise structure whose force distribution changes continuously during seismic events due to higher mode contribution, the three main mode shapes in each direction were considered to perform Modal Pushover Analyses (MPA) in this research [45-47]. For control point of the displacement of structure in all analyses, the center of mass at the roof level is selected. Since the relative lateral displacement (i.e., drift) of roof was used as a reference relative lateral displacement for plotting the capacity curves of the structures, two approaches were used to regulate the relative lateral displacement of structure. The first criterion for finishing the analysis is when the deformation capacity of each element is reached and the second one is when the limitation of reference drift and inter-story drift on the structure, which is $2 \%$ of building height, is based on Tables C1-3 of FEMA356 [44]. Therefore, the analysis stops when these drifts exceed the mentioned limit.

\subsection{Nonlinear modeling of RC shear wall}

To make the RC coupled shear wall sections, defining the linear and nonlinear characteristics of concrete and steel materials is necessary. The fiber cross-section elements, consisting of steel and concrete fibers, were used to model RC shear wall. ACI 318-05 requires confinement in boundary zones, when structural walls do not have the ability to deform their maximum displacement without exceeding the ultimate concrete compressive strains. Adding confinement allows the concrete to exhibit higher compressive strains without a significant degradation in strength, as illustrated in Figure 7. In PERFORM3D software, the stress-strain curve of confinement concrete is selected in the form of trilinear with strength loss and its tension strength is ignored. Figure 8 shows that the strain of the ultimate strength of concrete $\varepsilon_{L}$ is taken as 0.0171 , the strain of crushing limit of concrete $\varepsilon_{c u}$ as 0.04 , and the strain of yielding strength of concrete $\varepsilon_{Y}$ as 0.0034 . Further, $E_{c}$ (modulus of elasticity) is $200000 \mathrm{~kg} / \mathrm{cm}^{2}$. The stressstrain relationship of steel bar needs to be bilinear (elastic-perfectly plastic) without strength loss. The

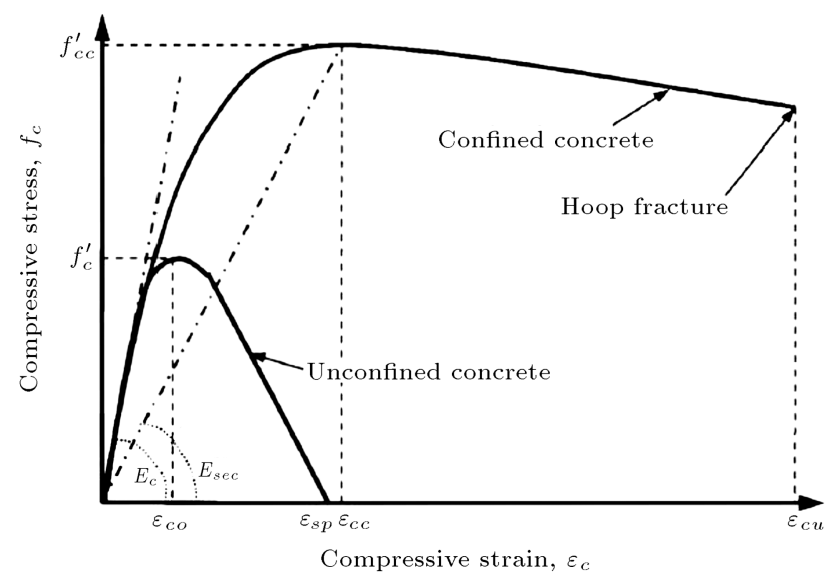

Figure 7. Stress-strain relationship for concrete in compression [48].

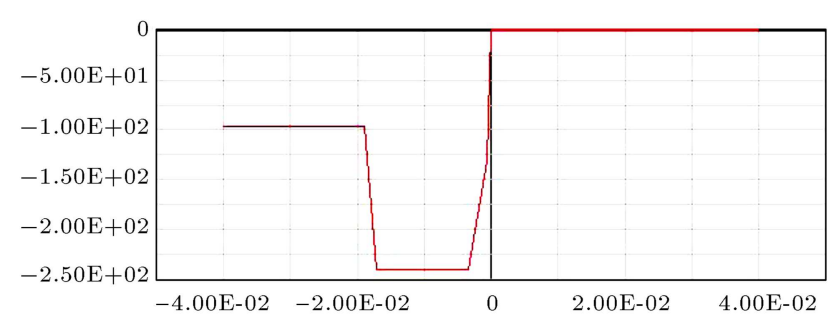

Figure 8. Nonlinear properties of concrete material. 


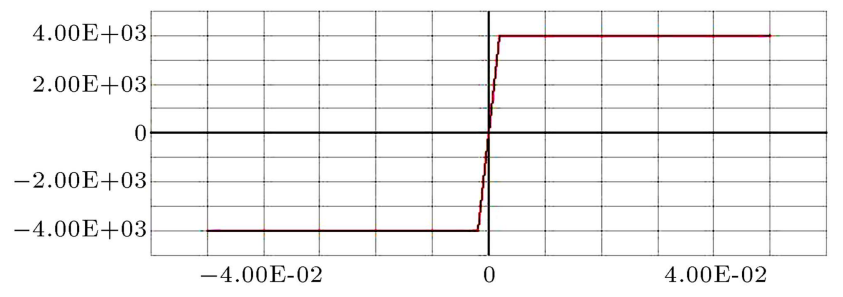

Figure 9. Modeling of the steel behavior.

modulus of elasticity, $E_{s}$, is taken as $2100000 \mathrm{~kg} / \mathrm{cm}^{2}$ and ultimate strain, $\varepsilon_{s u}$, as 0.05 according to Figure 9. In addition, yielding strength, $F_{y}$, is $4000 \mathrm{~kg} / \mathrm{cm}^{2}$.

\subsection{Nonlinear modeling of coupling beams}

To define the nonlinear characteristics of concrete coupling beam, model of shear hinge-displacement type in PERFORM3D was used (Figure 10). To assign nonlinear characteristics of concrete coupling beams, according to Tables 6-18 of FEMA-356 [44], plastic hinge rotation of diagonal reinforcement $(\theta)$ was estimated 0.05 . Therefore, $\Delta=L \theta$ where $L$ is coupling beam length. Shear force takes into account the two components: $V_{S}+V_{c}$ where $V_{S}$ is the contribution of diagonal reinforcement and $V_{c}$ is the contribution of concrete and calculated based on ACI 318-05 as follows:

$$
\begin{aligned}
& V_{S}=2 A_{S} F_{y} \sin \alpha, \\
& V_{c}=0.53 \sqrt{f_{c}^{\prime}} b_{w} d,
\end{aligned}
$$

where $A_{S}, F_{y}$, and $\alpha$ are cross-section area, yielding stress, and angle of diagonal rebar with respect to the horizontal plane in concrete coupling beam; $b_{w}$ and $d$ are width and effective depth of concrete coupling beam section.

As mentioned previously, steel coupling beams provide the same structural role as link beams in eccentrically braced frames. Moreover, to define nonlinear characteristics of steel coupling beam, model of shear hinge-displacement type in PERFORM3D was used (Figure 10). For steel coupling beams, according to Tables 5 and 6 of FEMA-356 [44], plastic hinge rotation of EBF link beam $(\theta)$ is taken as 0.17 and shear force equals $0.6 F_{y} A_{w}$.

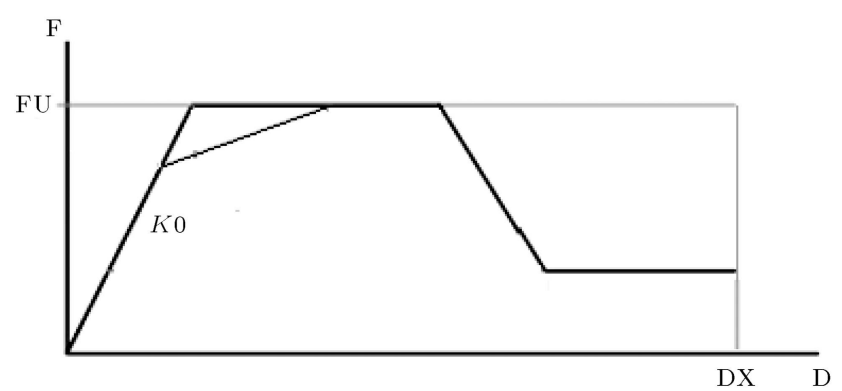

Figure 10. Modeling of the nonlinear behavior of coupling beam in PERFORM3D.

\section{Discussion and results of nonlinear analysis}

The story drift ratio plots of steel and reinforced concrete coupling beams at the target and ultimate levels are shown in Figures 11 to 13. These illustrate that although steel coupling beams have been designed based on the criterion of sufficient strength and shear yielding members, both of them (i.e., steel and rein-

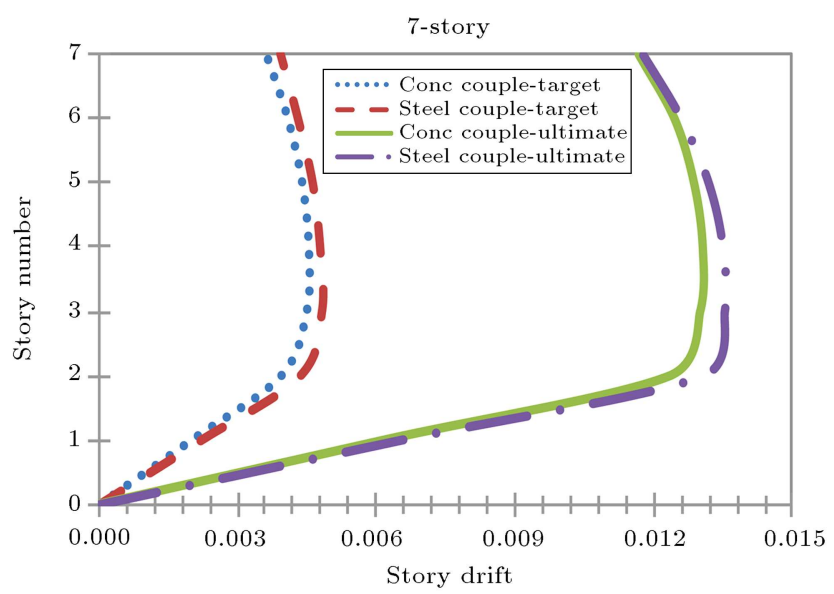

Figure 11. Story drift ratio at two levels for 7-story models.

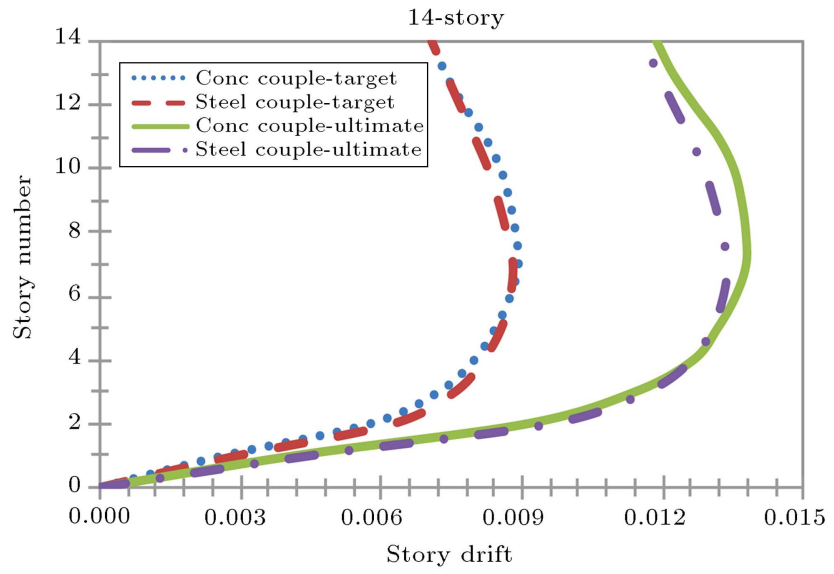

Figure 12. Story drift ratio at two levels for 14-story models.

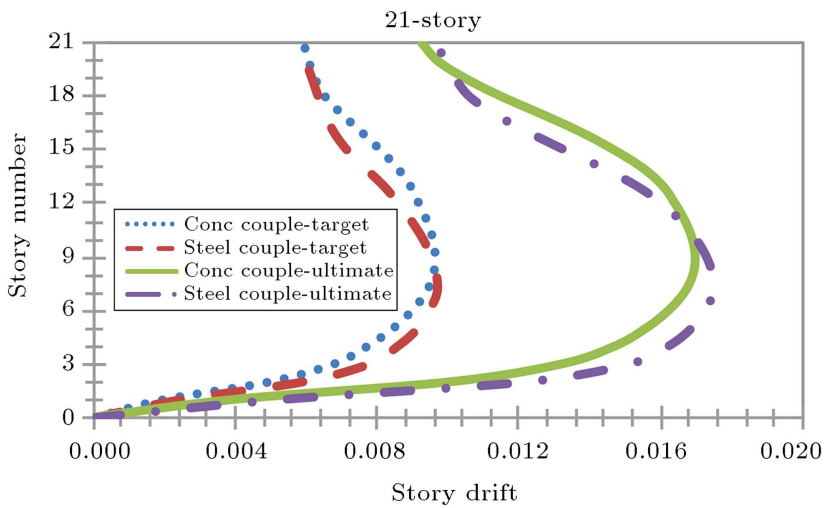

Figure 13. Story drift ratio at two levels for 21-story models. 
forced concrete coupling beams) approximately have the same drift distribution over the height.

The capacity curves of models, obtained by the pushover procedures, are shown in Figures 14 to 25 . They show that the capacity curves of the structural systems with shear wall ( $X$ direction) sharply drop before the ultimate displacement, but bearing capacity of the structural systems with coupled shear wall ( $Y$ direction) shows no sudden changes until the ultimate displacement. In addition, the UNSP

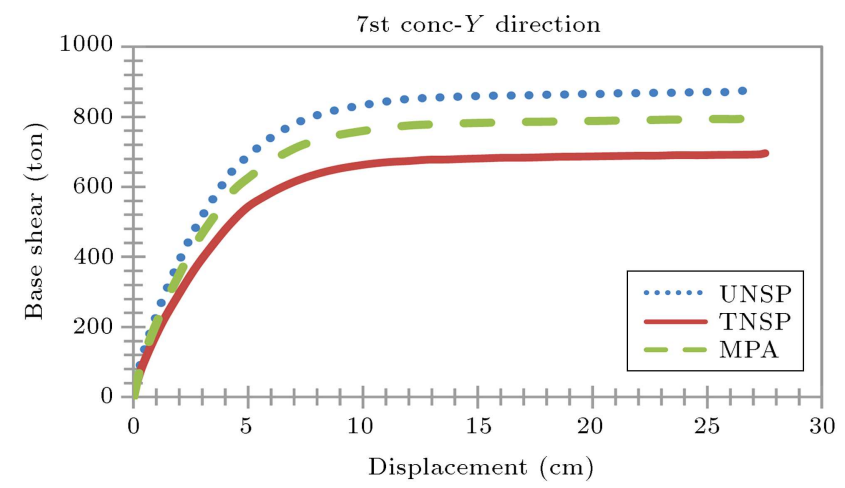

Figure 14. Capacity curves of Model 1 in $Y$ direction.

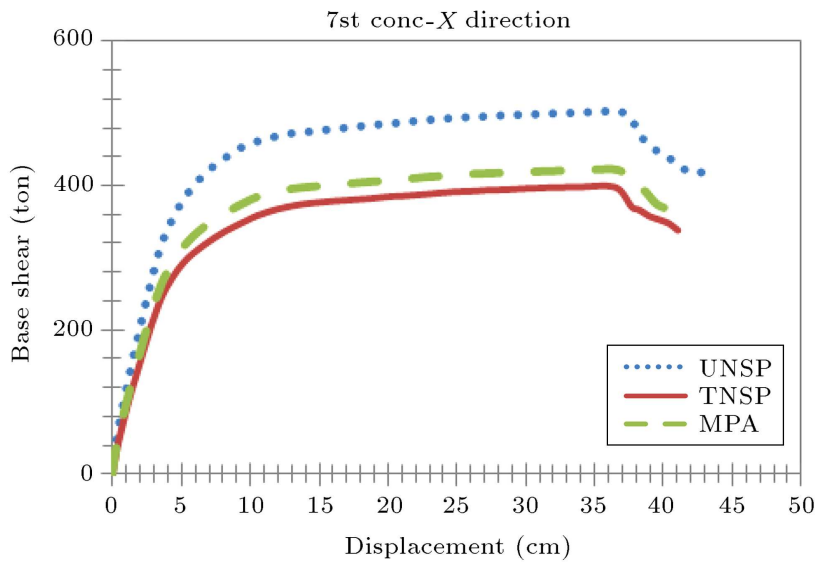

Figure 15. Capacity curves of Model 1 in $X$ direction.

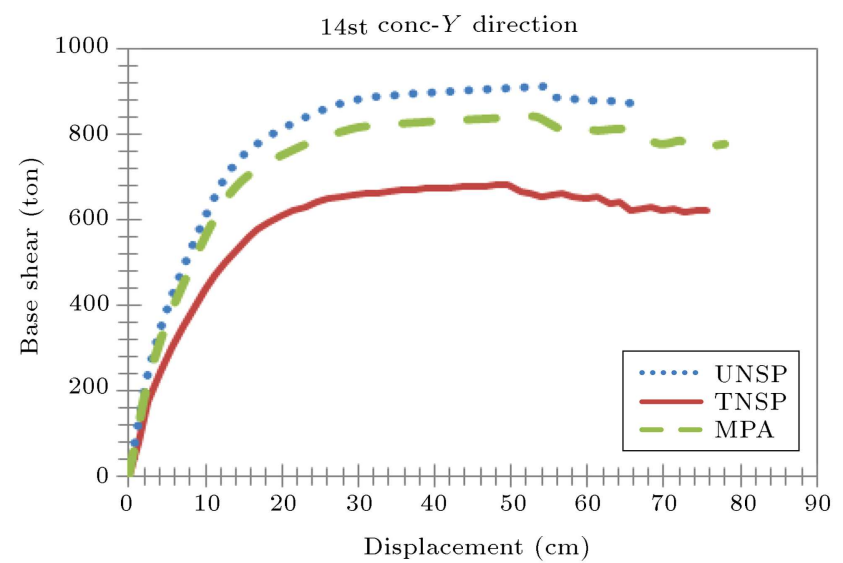

Figure 16. Capacity curves of Model 2 in $Y$ direction.

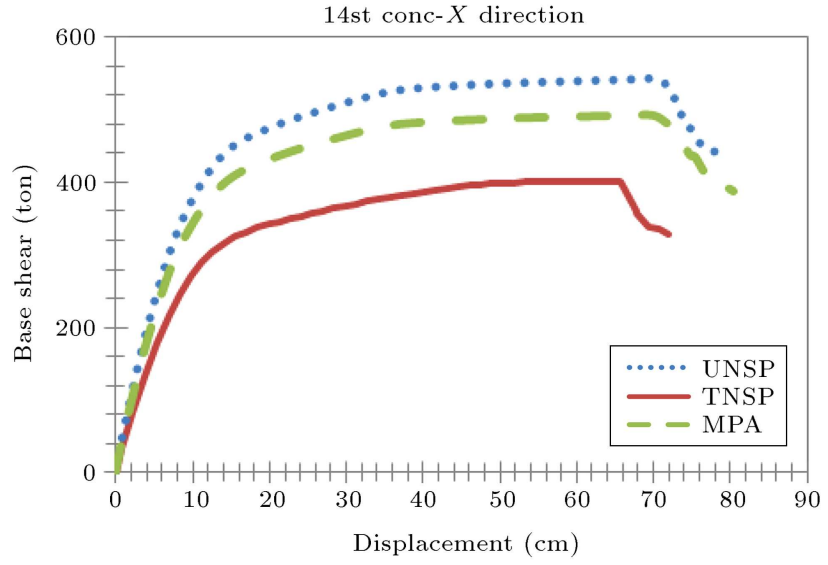

Figure 17. Capacity curves of Model 2 in $X$ direction.

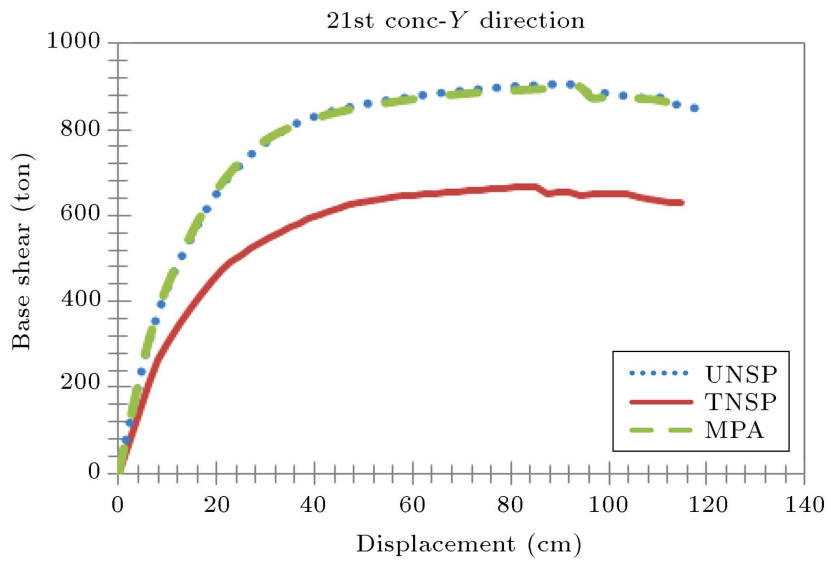

Figure 18. Capacity curves of Model 3 in $Y$ direction.

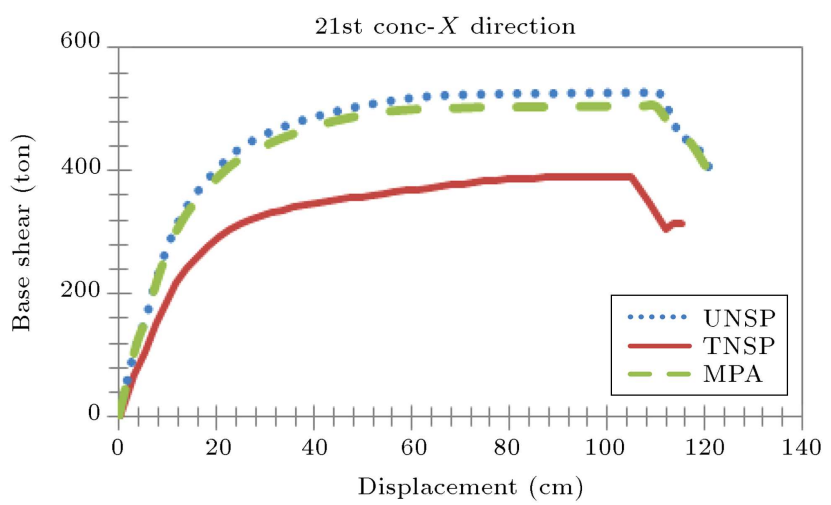

Figure 19. Capacity curves of Model 3 in $X$ direction.

procedure presents greater lateral strength values, the TNSP procedure with less lateral strength values, and MPA procedure is predicted between the two previous procedures. This difference can explain the effect of load pattern. Note that the three main mode shapes predicted by MPA procedures in both directions of structural plan are selected to perform modal pushover analyses and it is crucial for highrise structures. According to the figures, whatever the height goes up (21st models), MPA and UNSP 


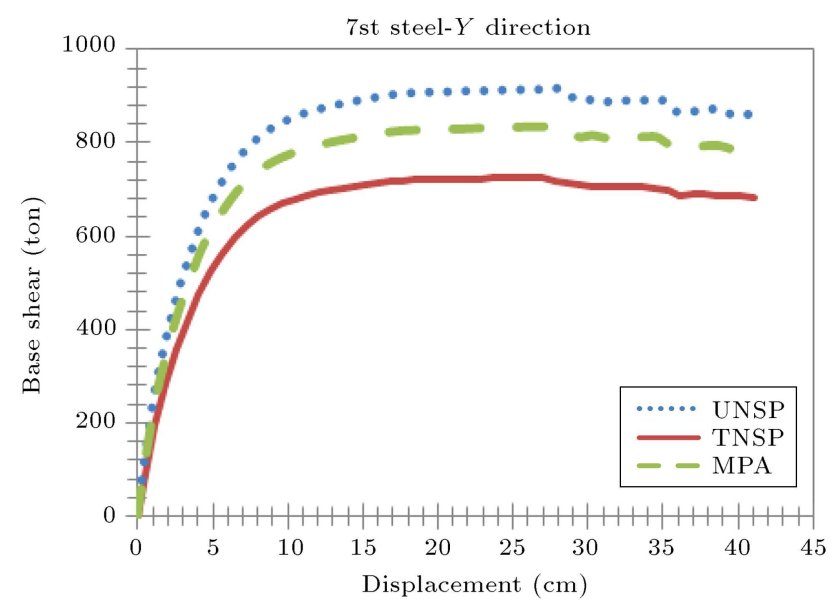

Figure 20. Capacity curves of Model 4 in $Y$ direction.

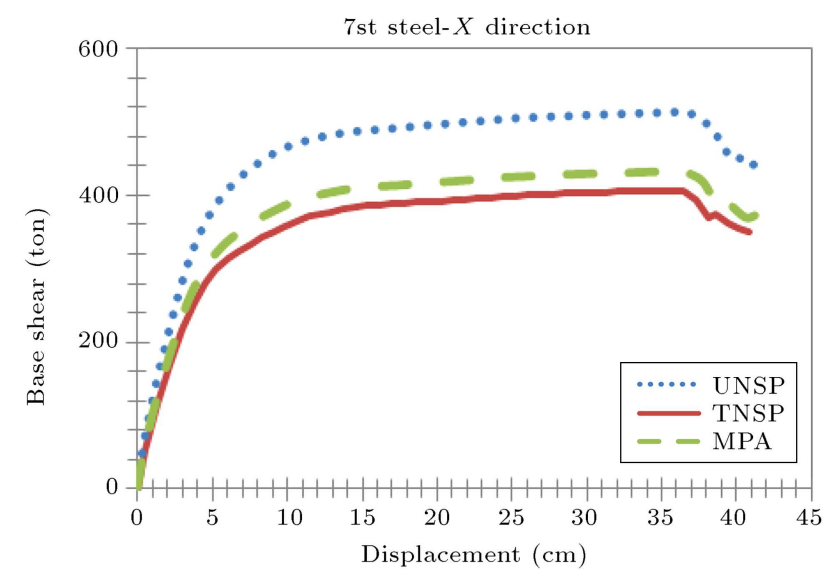

Figure 21. Capacity curves of Model 4 in $X$ direction.

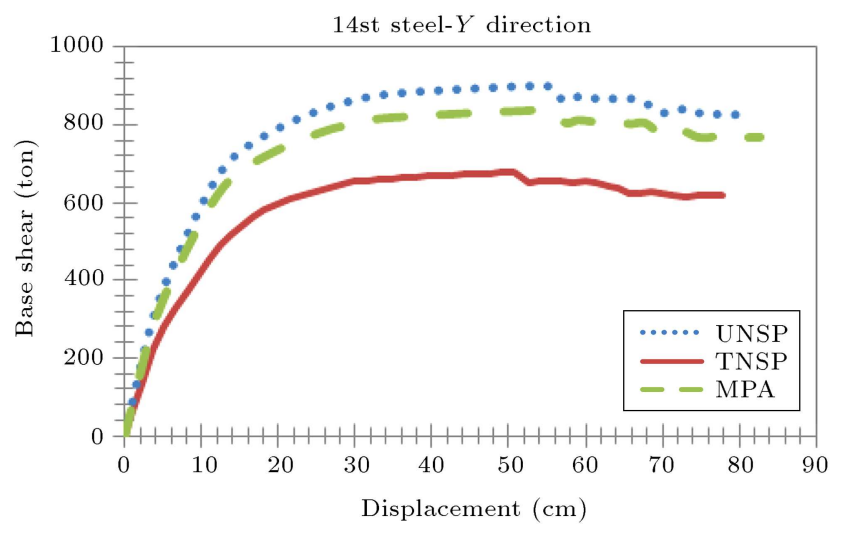

Figure 22. Capacity curves of Model 5 in $Y$ direction.

curves get closer and show the same trend. This can explain the importance of considering the higher mode shapes in pushover analysis. Also, these figures show that capacity curves of coupled shear wall ( $Y$ direction) with steel coupling beam based on MPA procedure are similar to the results of UNSP procedure; however, in structural systems with shear wall ( $X$ direction), those are close to the results obtained by TNSP procedure.

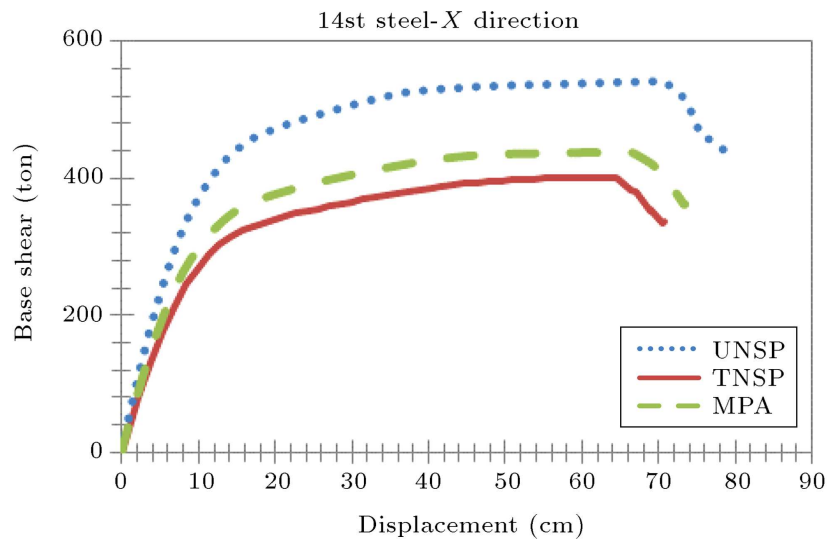

Figure 23. Capacity curves of Model 5 in $X$ direction.

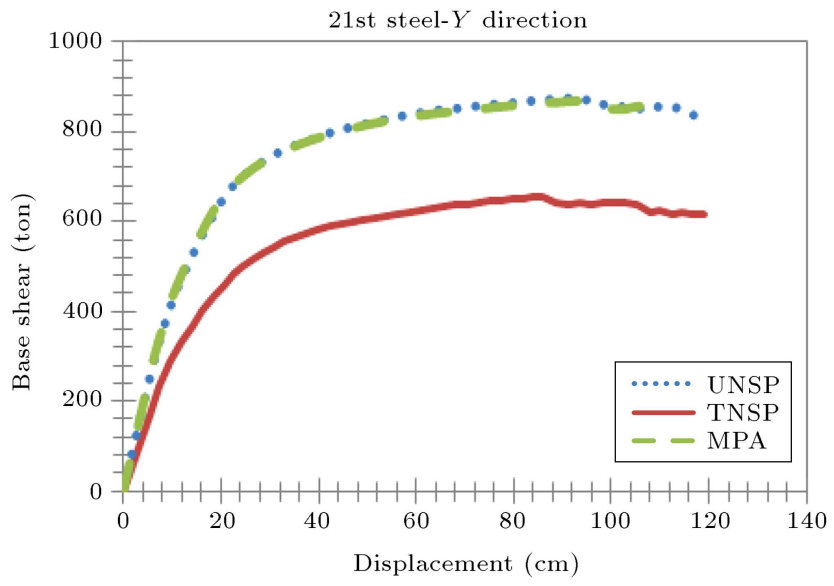

Figure 24. Capacity curves of Model 6 in $Y$ direction.

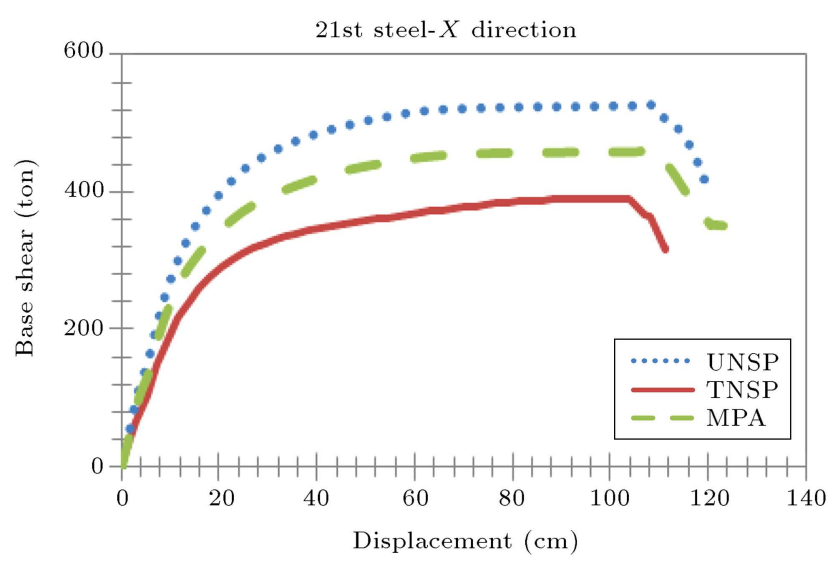

Figure 25. Capacity curves of Model 6 in $X$ direction.

Based on the obtained capacity curves, seismic parameters of structures have been calculated by using the equations, defined in Section 2, as indicated in Table 3. For better and more explicit assessment of $R$ and $C_{d}$ values, the average of the aforementioned values is shown in Table 4 . Finally, the mean values of $R$ and $C_{d}$ parameters obtained through this study are compared with some codes in Table 5 .

The results in Table 3 illustrate that force re- 
Table 3. The structural properties of models in nonlinear analysis and the seismic parameters of them.

\begin{tabular}{|c|c|c|c|c|c|c|c|c|c|}
\hline Model & Direction \& analysis & $V_{S}(\mathrm{~kg})$ & $D_{U}$ & $D_{y}$ & $V_{y}(\mathrm{~kg})$ & $\boldsymbol{R}_{S}$ & $\boldsymbol{\mu}, \boldsymbol{R}_{\mu}$ & $\boldsymbol{Y}$ & $R, C_{d}$ \\
\hline 7 st-conc & Y-UNSP & 733796.3 & 0.0118 & 0.00194 & 800000 & 1.1 & 6.08 & 1 & 6.7 \\
\hline 7 st-conc & X-UNSP & 428551.7 & 0.016 & 0.00209 & 450000 & 1.05 & 7.66 & 1 & 8 \\
\hline 7 st-conc & Y-TNSP & 575177.2 & 0.012 & 0.0021 & 672900 & 1.17 & 5.72 & 1 & 6.7 \\
\hline 7 st-conc & X-TNSP & 328080.8 & 0.0157 & 0.0021 & 351700 & 1.07 & 7.48 & 1 & 8 \\
\hline 7 st-conc & Y-MPA & 668418.3 & 0.0118 & 0.00197 & 848700 & 1.27 & 5.98 & 1 & 7.6 \\
\hline 7 st-conc & X-MPA & 352305.2 & 0.0158 & 0.0021 & 374000 & 1.06 & 7.52 & 1 & 8 \\
\hline 14 st-conc & Y-UNSP & 665626.6 & 0.0148 & 0.0029 & 866900 & 1.3 & 5.12 & 1 & 6.66 \\
\hline 14 st-conc & X-UNSP & 454421 & 0.0155 & 0.0024 & 484400 & 1.07 & 6.46 & 1 & 6.91 \\
\hline 14 st-conc & Y-TNSP & 471507.3 & 0.0166 & 0.00323 & 612900 & 1.3 & 5.14 & 1 & 6.68 \\
\hline 14 st-conc & X-TNSP & 325626.7 & 0.0144 & 0.0023 & 341900 & 1.05 & 6.26 & 1 & 6.6 \\
\hline 14 st-conc & Y-MPA & 617018.9 & 0.0172 & 0.00306 & 824400 & 1.34 & 5.63 & 1 & 7.5 \\
\hline 14 st-conc & X-MPA & 407489.6 & 0.0155 & 0.00241 & 438800 & 1.08 & 6.43 & 1 & 6.9 \\
\hline 21 st-conc & Y-UNSP & 597064.4 & 0.0175 & 0.00337 & 734300 & 1.23 & 5.2 & 1 & 6.4 \\
\hline 21 st-conc & X-UNSP & 427691.5 & 0.0161 & 0.00255 & 472600 & 1.1 & 6.3 & 1 & 6.9 \\
\hline 21 st-conc & Y-TNSP & 445821.1 & 0.017 & 0.00346 & 579500 & 1.3 & 4.9 & 1 & 6.4 \\
\hline 21 st-conc & X-TNSP & 313728.9 & 0.0155 & 0.0025 & 329600 & 1.05 & 6.2 & 1 & 6.5 \\
\hline 21 st-conc & Y-MPA & 628856.9 & 0.0169 & 0.00314 & 845800 & 1.34 & 5.38 & 1 & 7.21 \\
\hline 21 st-conc & X-MPA & 410029.9 & 0.0159 & 0.00255 & 455200 & 1.1 & 6.2 & 1 & 6.8 \\
\hline 7 st-conc & Y-UNSP & 727831.1 & 0.0179 & 0.00238 & 894500 & 1.23 & 7.52 & 1 & 9.25 \\
\hline 7 st-conc & X-UNSP & 434441.1 & 0.016 & 0.00213 & 461300 & 1.06 & 7.52 & 1 & 8 \\
\hline 7 st-conc & Y-TNSP & 562415.1 & 0.0179 & 0.00252 & 714400 & 1.27 & 7.12 & 1 & 9.04 \\
\hline 7 st-conc & X-TNSP & 334477.5 & 0.0159 & 0.00215 & 361700 & 1.08 & 7.4 & 1 & 8 \\
\hline 7 st-conc & Y-MPA & 663964.2 & 0.0179 & 0.0024 & 814300 & 1.23 & 7.45 & 1 & 9.2 \\
\hline 7 st-conc & X-MPA & 359665.6 & 0.0158 & 0.00214 & 384800 & 1.07 & 7.39 & 1 & 8 \\
\hline 14 st-conc & Y-UNSP & 689278.1 & 0.0182 & 0.00312 & 964000 & 1.4 & 5.83 & 1 & 7.9 \\
\hline 14 st-conc & X-UNSP & 448677.5 & 0.0156 & 0.0024 & 477700 & 1.065 & 6.5 & 1 & 6.92 \\
\hline 14 st-conc & Y-TNSP & 454248.7 & 0.0171 & 0.00327 & 658600 & 1.45 & 5.24 & 1 & 7.6 \\
\hline 14 st-conc & X-TNSP & 323573.4 & 0.0142 & 0.0023 & 341500 & 1.06 & 6.2 & 1 & 6.6 \\
\hline 14 st-conc & Y-MPA & 641769 & 0.0182 & 0.00308 & 823000 & 1.3 & 5.92 & 1 & 7.7 \\
\hline 14 st-conc & X-MPA & 355848.7 & 0.0148 & 0.0023 & 380500 & 1.07 & 6.43 & 1 & 6.9 \\
\hline 21 st-conc & Y-UNSP & 594331.2 & 0.0173 & 0.0031 & 814300 & 1.4 & 5.59 & 1 & 7.83 \\
\hline 21 st-conc & X-UNSP & 420822.5 & 0.0161 & 0.00256 & 470000 & 1.1 & 6.29 & 1 & 6.9 \\
\hline 21 st-conc & Y-TNSP & 431624.6 & 0.0176 & 0.00338 & 530800 & 1.23 & 5.2 & 1 & 6.4 \\
\hline 21 st-conc & X-TNSP & 311243.3 & 0.0154 & 0.00249 & 326400 & 1.05 & 6.18 & 1 & 6.5 \\
\hline 21 st-conc & Y-MPA & 593588.9 & 0.0163 & 0.00284 & 785500 & 1.32 & 5.73 & 1 & 7.56 \\
\hline 21 st-conc & X-MPA & 357756.3 & 0.0156 & 0.00253 & 404000 & 1.1 & 6.17 & 1 & 6.8 \\
\hline
\end{tabular}

Table 4. The mean value of $\left(R\right.$ and $\left.C_{d}\right)$.

\begin{tabular}{ccccccc}
\hline & 7st-steel & 7st-conc & 14st-steel & 14st-conc & 21st-steel & 21st-conc \\
\hline $\begin{array}{c}\text { The mean value of the three } \\
\text { analyses in } X \text { direction }\end{array}$ & 8 & 8 & 6.81 & 6.8 & 6.7 & 6.7 \\
$\begin{array}{c}\text { The mean value of the three } \\
\text { analyses in } Y \text { direction }\end{array}$ & 9.2 & 7 & 7.7 & 6.95 & 7.26 & 6.67 \\
\hline
\end{tabular}


Table 5. Comparison of the mean value of $R$ and $C_{d}$ parameters obtained through this study with seismic codes.

\begin{tabular}{|c|c|c|c|c|c|c|c|c|c|c|}
\hline \multirow[t]{2}{*}{$\begin{array}{l}\text { Lateral force } \\
\text { resisting system }\end{array}$} & \multicolumn{5}{|c|}{$\begin{array}{l}\text { Response modification } \\
\text { factor or force } \\
\text { reduction factor }(R)\end{array}$} & \multicolumn{5}{|c|}{$\begin{array}{l}\text { Displacement amplification } \\
\text { factor }\left(C_{d}\right)\end{array}$} \\
\hline & $\begin{array}{l}\text { Standard } \\
\text { No. } 2800 \\
R=R_{w}\end{array}$ & $\begin{array}{c}\text { (Standard } \\
\text { No. 2800) } \\
\boldsymbol{R}_{u}=\boldsymbol{R}_{w} / \mathbf{1 . 4}\end{array}$ & $\begin{array}{l}\mathrm{UBC} 97 \\
R=R_{u}\end{array}$ & $\begin{array}{l}\text { IBC2000 } \\
R=R_{u}\end{array}$ & $\begin{array}{c}\text { This } \\
\text { research } \\
R=R_{u}\end{array}$ & $\begin{array}{l}\text { Standard } \\
\text { No. } 2800 \\
C_{d}=C_{d w}\end{array}$ & $\begin{array}{c}\text { (Standard } \\
\text { No. 2800) } \\
C_{d w} / \mathbf{1 . 4}\end{array}$ & $\begin{array}{c}\mathrm{UBC} 97 \\
C_{d}=C_{d u}\end{array}$ & $\begin{array}{c}\text { IBC2000 } \\
C_{d}=C_{d u}\end{array}$ & $\begin{array}{c}\text { This } \\
\text { research } \\
C_{d}=C_{d u}\end{array}$ \\
\hline $\begin{array}{c}\text { Intermediate } \\
\text { concrete } \\
\text { moment-resisting } \\
\text { frames } \\
\text { accompanied } \\
\text { with intermediate } \\
\text { reinforced concrete } \\
\text { shear wall }\end{array}$ & 8 & 5.7 & 6.5 & 5.75 & $\begin{array}{c}R_{1 x}=8 \\
R_{1 y}=7 \\
R_{2 x}=6.8 \\
R_{2 y}=6.95 \\
R_{3 x}=6.7 \\
R_{3 y}=6.67 \\
R_{4 x}=8 \\
R_{4 y}=9.6 \\
R_{5 x}=6.81 \\
R_{5 y}=7.7 \\
R_{6 x}=6.7 \\
R_{6 y}=7.26\end{array}$ & 4 & 4.55 & 4.75 & $\begin{array}{c}C_{d 1 x}=8 \\
C_{d 1 y}=7 \\
C_{d 2 x}=6.8 \\
C_{d 2 y}=6.95 \\
C_{d 3 x}=6.7 \\
C_{d 3 y}=6.67 \\
C_{d 4 x}=8 \\
C_{d 4 y}=9.2 \\
C_{d 5 x}=6.81 \\
C_{d 5 y}=7.7 \\
C_{d 6 x}=6.7 \\
C_{d 6 y}=7.26\end{array}$ & \\
\hline
\end{tabular}

Note: $R_{i x}$ is the force reduction factor of $i$ model in $X$ direction;

$R_{i y}$ is the force reduction factor of $i$ model in $Y$ direction;

$C_{d i x}$ is the displacement amplification factor of $i$ model in $X$ direction;

$C_{d i y}$ is the displacement amplification factor of $i$ model in $Y$ direction.

duction factor due to over-strength $\left(R_{S}\right)$ in structures with coupling beam ( $Y$ direction) is generally more than that in structures without coupling beam $(X$ direction), while ductility factor in structures without coupling beam ( $X$ direction) is more than structures with coupling beam ( $Y$ direction). As the structure height increases according to Table 3, first, the force reduction factor due to ductility $\left(R_{\mu}\right)$ decreases, and then remains constant approximately. However, the force reduction factor due to over-strength $\left(R_{S}\right)$ first increases, and then remains constant approximately. Furthermore, there is a decrease in $R$ and $C_{d}$ with rise in structure height, while the rate of decline is less at higher altitudes. For example, response modification factor of $R=8, R=6.8$, and $R=6.7$ is obtained for $7,14,21$ st-conc in $X$ direction, respectively, as it is observed that 7 st has much higher value of $R$ than 14 and 21 st do, and these values at 14 , and 21 st approach each other.

The mean values of $R$ are evaluated for similar moment-resisting $\mathrm{RC}$ frames with shear wall in the present study ranging from 6.67 to 9.2 . This can be concluded that the level of reference drift limit and the number of stories highly influence the value of $R$. Evaluation of the results in Tables 3 and 4 proves that at the structures with the same height, the values of $R$ and $C_{d}$ parameters in coupling shear wall structures with steel beam are higher than those in coupling shear wall structures with concrete beam, although these parameters have the same value with acceptable accuracy in concrete shear wall of the mentioned models ( $X$ direction). Finally, the mean values of $R$ and $C_{d}$ parameters obtained through this study are compared with some codes in Table 5. For the intermediate ductility concrete moment-resisting frames accompanied with intermediate ductility reinforced concrete shear wall, response modification factor of $R=5.7, R=6.5$, and $R=5.75$ is given by Standard No. 2800, UBC97 [49] and IBC2000 [50], respectively. It should be noted that $R$ factors given by UBC97 are generally higher than those given by Standard No. 2800 and IBC2000. According to the values obtained through this study, Standard No. 2800, UBC97, and IBC2000 slightly underestimate $R$ factor, especially for shorter structures. Furthermore, the same situation is valid in the case of $C_{d}$; for example, the lowest value obtained for $C_{d}$ is 6.67 , but according to Standard No. $2800, C_{d}$ factor that is suggested as 0.7 times of the response modification factor in this code equals 4 .

\section{Conclusion}

In this paper, the influence of steel and concrete coupling beams on the seismic behavior of dual structural systems in the form of concrete moment-resisting frames accompanied with RC coupled shear walls was evaluated. Some of the key results obtained by this evaluation are as follows:

1. RC coupling shear wall with steel and concrete coupling beams have the same drift distribution over the height until the ultimate displacement;

2. Capacity curves of structural systems with shear wall sharply drop before reaching the ultimate displacement, but bearing capacity of structural systems with coupled shear wall (steel or concrete 
coupling beam) shows no sudden changes until the ultimate displacement;

3. Capacity curves of coupled shear wall with steel coupling beam based on MPA procedure are similar to the results obtained by UNSP procedure; but, in structural systems with shear wall, those are close to results of TNSP procedure;

4. Factor of over-strength $\left(R_{S}\right)$ in structural systems with coupling shear wall is more than that in structural systems with shear wall, while ductility factor $\left(R_{\mu}\right)$ in structural systems with shear wall is more than that in structural systems with coupling shear wall;

5. The values of response modification factor $(R)$ and displacement amplification factor $\left(C_{d}\right)$ in coupling shear wall structures with steel coupling beam are higher than those of coupling shear wall structures with concrete coupling beam with the same height;

6. The amounts of response modification factor $(R)$ and displacement amplification factor $\left(C_{d}\right)$ obtained for coupling shear wall structures with concrete or steel coupling are more than suggested amounts by codes (example: Standard No. 2800, $\mathrm{UBC} 97$, and IBC2000).

\section{References}

1. Hemsas, M., Elachachi, S.M. and Breysse, D. "Evaluation of the seismic vulnerability of quasi symmetrical reinforced concrete structures with shear wall", European Journal of Environmental and Civil Engineering, 14(5), pp. 617-636 (2010).

2. El-Tawil, S., Kuenzli, C.M. and Hassan, M. "Pushover of hybrid coupled walls. I: design and modeling", Structural Engineering, 128(10), pp. 1272-1281 (2002a).

3. Aristizabal-Ochoa, J.D. "Seismic behavior of slender coupled wall systems", Structural Division, 113, pp. 2221-2234 (1987).

4. Aristizabal-Ochoa, J.D. "Dynamic response of coupled wall systems", Structural Division, 108, pp. 1846-1857 (1982).

5. Aktan, A.E. and Bertero, V.V. "The seismic resistant design of R/C coupled structural walls", Report No. UCB/EERC-81/07, Earthquake Engineering Research Center, University of California, Berkeley (1981).

6. Aktan, A.E. and Bertero, V.V. "Seismic response of R/C frame-wall structures", Structural Division, 110, pp. 1803-1821 (1984).

7. Aktan, A.E. and Bertero, V.V. "Evaluation of seismic response of RC building loaded to failure", Structural Division, 113, pp. 1092-1108 (1987).

8. Lybas, J.M. and Sozen, M.A. "Effect of beam strength and stiffness on dynamic behavior of reinforced concrete walls", Structural Research Series No. 444, University of Illinois, Urbana-Champaign (1977).
9. Shiu, N.K., Barney, G.B., Fiorato, A.E. and Corley, W.G. "Earthquake resistant walls-coupled wall test", Report to NSF submitted by Portland Cement Association, Research and Development, Skokie, Illinois (1981).

10. Shiu, N.K., Takayangi, T. and Corley, W.G. "Seismic behavior of coupled wall systems", Structural Division, 110, pp. 1051-1066 (1984).

11. Paulay, T. and Binney, J.R. "Diagonally reinforced concrete beams for shear walls", ACI Special Publication SP 42 - Shear in Reinforced Concrete, pp. 579-598 (1974).

12. Robert, P. and Paulay, T., Reinforced Concrete Structures, Wiley and Sons, New York (1975).

13. Shahrooz, B.M., Remmetter, M.A. and Qin, F. "Seismic design and performance of composite coupled walls", Structural Division, 119(11), pp. 3291-3309 (1993).

14. Cheng, M.Y., Fikri, R. and Chen, C.C. "Experimental study of reinforced concrete and hybrid coupled shear wall systems", Engineering Structures, 82, pp. 214-225 (2015).

15. Harries, K.A., Mitchell, D., Cook, W.D. and Redwood, R.G. "Seismic response of steel beams coupling reinforced concrete walls", Structural Engineering, 119(12), pp. 3611-3629 (1993).

16. El-Tawil, S. and Christopher, M. Kuenzli. "Pushover of hybrid coupled walls. II: Analysis and behavior", Structural Division, 128(10), pp. 1282-1289 (2002b).

17. Harries, K.A., Gong, B. and Shahrooz, B.M. "Behavior and design of reinforced concrete, steel and steelconcrete coupling beams", Earthquake Spectra, 16(4), pp. $775-799$ (2000).

18. Harries, K.A. "Ductility and deformability of coupling beams in reinforced concrete shear walls", Earthquake Spectra, 17(3), pp. 457-478 (2001).

19. Park, W.S. and Yun, H.D. "Seismic behavior of steel coupling beams linking reinforced concrete shear walls", Engineering Structures, 27, pp. 1024-1039 (2005).

20. El-Tawil, S., Harries, K., Fortney, P., Shahrooz, B.M. and Kurama, Y. "Seismic design of hybrid coupled wall systems: state of the art", Structural Engineering, 136(7), pp. 755-769 (2010).

21. Yahya, C.K. and Qiang, S. "Seismic design and response evaluation of unbounded post-tensioned hybrid coupled wall structures", Earthquake Engng. Struct. Dyn., 37, pp. 1677-1702 (2008).

22. Nie, J.G., Hua, H.S. and Eatherton, M.R. "Concrete filled steel plate composite coupling beams: Experimental study", Constructional Steel Research, 94, pp. 49-63 (2014). 
23. Khalifa, E.S. "Analytical model for steel fiber concrete composite short-coupling beam", Composites: Part B, 56, pp. 318-329 (2014).

24. Esmaeili, H., Kheyroddin, A., Kafi, M.A. and Nikbakht, H. "Comparison of nonlinear behavior of steel moment frames accompanied with RC shear walls or steel bracings", Struct. Design Tall Spec. Build., 22, pp. 1062-1074 (2011). DOI: 10.1002/tal.751

25. Akbari, R. and Maheri, M.R. "Analytical investigation of response modification (behavior) factor, $R$, for reinforced concrete frames rehabilitated by steel chevron bracing", Structure and Infrastructure Engineering, $\mathbf{9}(6)$, pp. 507-515 (2013).

26. Asghari, A. and Gandomi, A.H. "Ductility reduction factor and collapse mechanism evaluation of a new steel knee braced frame", Structure and Infrastructure Engineering (2015). DOI:10.1080/15732479.2015.1009123

27. Whittaker, A., Hart, G. and Rojahn, C. "Seismic response modification factors", Structural Engineering, 125(4), pp. 438-444 (1999).

28. Kim, J. and Choi, H. "Response modification factors of Chevron-Braced frames", Engineering Structures, 27, pp. 285-300 (2005).

29. Khalili, A., Kheyroddin, A., Farahani, A. and Sharbatdar, M.K. "Nonlinear behavior of RC frames strengthened with steel curb and prop", Scientia Iranica, Transactions A: Civil Engineering, 22(25), pp. 1712$1722(2015)$.

30. Asgarian, B. and Shokrgozar, H.R. "BRBF response modification factor", Constructional Steel Research, 65, pp. 290-298 (2009).

31. New Mark, N.M. and Hall, W.J. "Earthquake spectra and design", Engineering Monograph, Earthquake Engineering Research Institute, Berkeley, California (1982).

32. Su, R.K.L, Lam, W.Y. and Pam, H.J. "Experimental study of plate reinforced composite deep coupling beams", Struct. Design Tall Spec. Build., 18(3), pp. 235-257 (2009). DOI: $10.1002 /$ tal.407

33. Subedi, N.K., Marsono, A.K. and Aguda, G. "Analysis of reinforced concrete coupled shear wall structures", Struct. Design Tall Spec. Build., 8(2), pp. 117-143 (1999).

34. Kwan, A.K.H. and Zhao, Z.Z. "Cyclic behavior of deep reinforced concrete coupling beams", Proceedings of the Institution of Civil Engineers-Structures and Buildings, 152, pp. 283-293 (2002a).

35. Harries, K.A. and Mcneice, D.S. "Performance-Based design of high rise coupled wall systems", Struct. Design Tall Spec. Build., 15(3), pp. 289-306 (2006). DOI: $10.1002 /$ tal.296
36. Hosseini, M., Sadeghi, H. and Habiby, S.A. "Comparing the nonlinear behaviors of steel and concrete link beams in coupled shear walls system by finite element analysis", Procedia Engineering, 14, pp. 28642871 (2011).

37. Harries, K.A. "Ductility and deformability of coupling beams in reinforced concrete coupled walls", Proceedings of the Eighth Canadian Conference on Earthquake Engineering, Vancouver, Canada, pp. 475-481 (1998).

38. Saatcioglu, M., Derecho, A.T. and Corley, W.G. "Parametric study of earthquake-resistant coupled walls", Structural Division, 113(1), pp. 141-157 (1987).

39. American Institute for Steel Construction (AISC). Specification for structural steel buildings (2010).

40. Marcakis, K. and Mitchell, D. "Precast concrete connections with embedded steel members", Prestressed Concrete Institute, 25(4), pp. 88-116 (1980).

41. Mattock, A.H. and Gaafar, G.H. "Strength of embedded steel section as brackets", ACI., 79 (2) (1982).

42. Building and Housing Research Center, Iranian Code of Practice for Seismic Resistant Design of Buildings [Standard No. 2800, 3th Edition], Tehran, Iran, (2007).

43. American Concrete Institute, Building Code Requirements for Structural Concrete (ACI 318-05) (2005).

44. Federal Emergency Management Agency, FEMA-356. Prestandard and Commentary for the Seismic Rehabilitation of Buildings. Washington, USA (2000).

45. Chopra, A.K. and Goel, R.K. "A modal pushover analysis procedure for estimating seismic demands for buildings", Earthquake Engineering \& Structural Dynamics, 31, pp. 561-582 (2002).

46. Rayes, J.C. and Chopra, A.K. "Evaluation of threedimensional modal pushover analysis for unsymmetricplan buildings subjected to two components of ground motion", Earthquake Engineering \& Structural Dynamics, 40, pp. 1475-1494 (2011).

47. Hashemi, M.J. and Mofid, M. "Evaluation of energybased modal pushover analysis in reinforced concrete frames with elevation irregularity", Scientia Iranica, Transaction A: Civil Engineering, 17(2), pp. 96-106 (2010).

48. Priestley, M.J.N., Calvi, G.M. and Kowalsky, M.J. "Displacement-based seismic design of structures", Pavia, Italy (2007).

49. Uniform Building Code (UBC), International conference of building officials, Wihttier, California (1997).

50. International Building Code (IBC), International conference of building officials, Wihttier, California, (2000).

\section{Biographies}

Habib Akbarzadeh Bengar is an Assistant Professor of the Department of Civil Engineering at the University of Mazandaran. His research interests include 
the strengthening of reinforced concrete structures with FRP, flexural behavior of high strength concrete members, behavior of fiber reinforced concrete member in flexure and compression, and seismic behavior and design of reinforced concrete frame and shear wall system.
Roja Mohammadalipour Aski is an MSc student of the Department of Civil Engineering at the Shomal University. Her research interests include the seismic behavior and design of reinforced concrete frame and shear wall system. 